\title{
The Role of Ability Judgments in Self-Handicapping
}

\author{
Sean M. McCrea \\ Edward R. Hirt \\ Indiana University-Bloomington
}

\begin{abstract}
This research investigated whether self-handicapping preserves specific conceptions of ability in a particular domain despite poor performance. Reports of preparatory behaviors and stress among introductory psychology students were measured prior to an exam and subsequent performance, attributions for the performance, and measures of global self-esteem and specific selfconceptions were measured after the exam. Results indicated that high self-handicappers reported reduced effort and more stress prior to the exam, performed worse on the exam, and made different attributions following the exam than did low self-handicappers. Although reported self-handicapping was detrimental to performance, male HSH individuals maintained positive conceptions of specific ability in psychology in spite of poorer performance. Moreover, the results of path analyses indicated that it was these changes in specific ability beliefs that mediated changes in global self-esteem. These findings suggest that the primary motivation underlying self-handicapping may be to protect conceptions of ability in a specific domain, which thereby serves to protect global self-esteem.
\end{abstract}

$\mathbf{S}$ elf-handicapping is a self-protective strategy in which individuals erect an impediment to success to control attributions following a performance. As originally formulated by Jones and Berglas (1978), self-handicapping relies on the attributional principles of discounting and augmenting (Kelley, 1973): The impact of ability as the causal factor of performance is influenced by the presence of another potential causal factor (the handicap). By erecting an impediment to success, the psychological impact of any failure will be softened because the failure can be attributed to the handicap rather than a lack of ability. Conversely, a success will be bolstered and lead to stronger ability attributions because the individual was able to succeed despite the handicap.

The present research is designed to explore the underlying motivation behind self-handicapping. A great deal of recent attention has been devoted to this question. In its original formulation (Jones \& Berglas, 1978), self-handicapping was thought to be motivated by a need to protect global self-esteem. This motivation has been shown to be enhanced by anticipated threats to selfesteem (Snyder \& Smith, 1982) or manipulations (e.g., noncontingent success feedback) that create uncertainty about one's ability (Berglas \& Jones, 1978). In addition, the finding that self-handicapping is exacerbated in conditions where the outcome of a performance will be known by others implies that self-presentational or impression management concerns also may motivate selfhandicapping (Arkin \& Baumgardner, 1985; Kolditz \& Arkin, 1982). Based on these findings, it is generally accepted that a combination of motives, such as impression management concerns, self-esteem needs, and a desire for perceived control over the environment, are important to the self-handicapper (Arkin \& Baumgardner, 1985; Snyder, 1990).

Clearly, one important aspect of self-handicapping is the desire to protect self-esteem. To evaluate the effectiveness of self-handicapping in this regard, researchers have examined the consequences of self-handicapping for the self. Specifically, the self-handicapper should show evidence of augmenting self-attributions of ability following success and discounting self-attributions of ability following failure. Furthermore, these attributions should allow the individual to maintain global selfesteem in the event of failure (self-protection) as well as enhance global self-esteem in the event of success (self-

Authors' Note: Address correspondence to Sean M. McCrea or Edward R. Hirt, Department of Psychology, Indiana University, 1101 East 10th St., Bloomington, IN 47405-7007; e-mail: smccrea@indiana.edu or ehirt@ indiana.edu. 
enhancement). Thus, global self-esteem should be affected via ability attributions.

\section{Attribution and Self-Esteem Evidence}

Several studies have reported discounting of ability by self-handicappers subsequent to a failure (Berglas \& Jones, 1978; Isleib, Vuchinich, \& Tucker, 1988; Mayerson \& Rhodewalt, 1988). However, there has been some inconsistency regarding whether self-handicappers attribute the failure to the actual handicap or other external factors such as luck (Murray \& Warden, 1991; Rhodewalt \& Hill, 1995). Effort, while providing a protective excuse for failure, is still an internal attribution and may be less preferable than an external attribution that has no evaluative implications for the self. These findings are consistent with the view that self-handicappers are motivated to protect against possible negative consequences when a performance outcome is unlikely to be positive.

Despite the prediction that self-handicappers should augment a success, most studies have failed to find evidence of augmenting in postperformance attributions. Indeed, self-handicapping appears to be motivated more by a desire for self-protection as opposed to selfenhancement (Murray \& Warden, 1991). However, augmentation has been found with low-achievement motivation students following a low-effort success (Touhey \& Villemez, 1980) and among individuals high in selfesteem who have either engaged in self-handicapping (Tice, 1991) or who have been identified as high trait self-handicapping individuals (Rhodewalt, Morf, Hazlett, \& Fairfield, 1991). In general, self-handicappers seem reluctant to enhance ability attributions. Augmenting success may be considered too risky for the selfhandicappers because doing so only raises the expectations of others and may necessitate conquering the task yet again.

Several studies have attempted to demonstrate that self-handicapping also preserves overall self-esteem. The results of these studies have provided fairly consistent support for this notion. Several studies have found that individuals who self-handicapped maintained high levels of self-esteem following failure (Rhodewalt \& Hill, 1995; Rhodewalt et al., 1991; but see Isleib et al., 1988, for a notable exception). In contrast, individuals who did not self-handicap in these studies (or did not have a self-handicap available to them) reported lower self-esteem following failure. These studies also demonstrated, using regression-based path analyses, that the effects of self-handicapping on self-esteem were mediated by ability attributions, supporting the original Jones and Berglas (1978) conceptualization. Thus, self-handicapping appears to serve the self-protective function of preserving self-esteem in the face of poor performance.

Evidence for self-enhancement following success has been more equivocal. Rhodewalt et al. (1991) found evidence of augmentation following self-handicapping for high-self-esteem (HSE) individuals who were also high in trait self-handicapping. A recent study by Feick and Rhodewalt (1997) found evidence of more extreme ability attributions as well as elevated self-esteem following success in a naturalistic setting. Moreover, these results were obtained for both HSE and low-self-esteem (LSE) individuals, unlike previous research (Rhodewalt et al., 1991; Tice, 1991). Feick and Rhodewalt argued that this may be the consequence of performing the study in a field (i.e., classroom) setting outside the laboratory, where self-presentational motives may be less active. In any event, these results provide strong support for the notion that self-handicapping preserves (or enhances) global self-esteem via attributions to ability.

\section{What About Ability Beliefs?}

The assumption implicit in these predictions has been that global self-esteem is protected by self-handicapping because underlying conceptions of ability that are important to the self are maintained or enhanced. However, the only evidence for this explanation has come from the discounting or augmenting of ability attributions following the performance rather than a direct examination of ability beliefs. Therefore, one could reasonably ask what self-handicappers actually believe about their own abilities following a performance. Thus, the first goal of the present research was to examine the ability beliefs of self-handicappers following performance. We expected that self-handicapping would maintain conceptions of ability as well as global self-esteem. Moreover, we predicted that performance attributions will mediate these changes in ability beliefs, as Rhodewalt and his colleagues (Rhodewalt \& Hill, 1995; Rhodewalt et al., 1991) have demonstrated with regard to changes in global self-esteem.

Thus, we argue that performance attributions mediate changes in both ability beliefs and global self-esteem for self-handicappers. These predictions raise an interesting question regarding the relationship between these two proposed attributional benefits of self-handicapping. It is conceivable that these represent two largely independent consequences of self-handicapping. Alternatively, it could be that one of these consequences is derivative of the other. One possibility is that attributions following self-handicapping behavior serve to protect important ability beliefs, which in turn bolster selfesteem. This relationship would suggest that protected ability judgments are the source of benefits for self- 
(a)

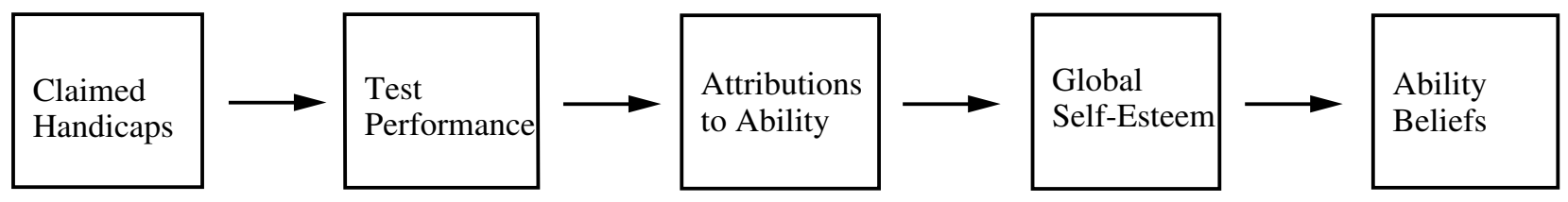

(b)

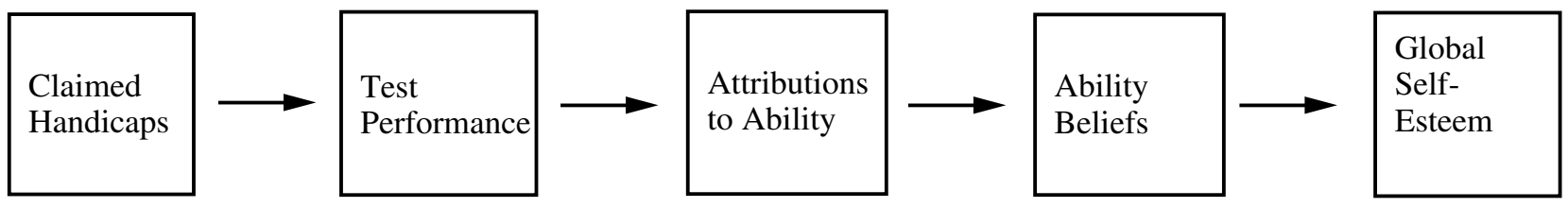

Figure 1 Alternative causal pathways concerning the relationships between self-handicapping, global self-esteem, and ability beliefs.

esteem, a prediction consistent with Berglas and Jones's (1978) original conceptualization. However, a second possibility involves the reverse relationship, that changes in global self-esteem following a handicapped performance affect judgments of ability. In this case, selfesteem would be the source of benefits to judgments of ability: Because individuals have higher global selfesteem following performance, they rate themselves higher in terms of ability. Thus, a second goal of the present work was to examine the nature of the relationship between ability beliefs and global self-esteem following a handicapped performance.

Indeed, the answer to this question has important implications for our conceptualization of self-handicapping. If self-handicapping is primarily motivated by a desire to maintain global self-esteem, then it shares a number of similarities with other self-protective mechanisms. Indeed, Tesser, Martin, and Cornell (1996) have recently discussed how many different members of the so-called self-zoo (e.g., self-affirmation, self-evaluation maintenance $[\mathrm{SEM}]$ processes) share the same underlying motivation of maintaining positive self-regard and have shown that several of these different self-mechanisms can effectively substitute for one another. However, if self-handicapping is primarily motivated by a desire to maintain ability beliefs within a specific domain, then it may be relatively unique among the members of the selfzoo. The present study is a first step in such an investigation, attempting to demonstrate that protection of specific beliefs is an important additional benefit of selfhandicapping and to examine the direction of the relationship (if any) between ability beliefs and global selfesteem.

How would one determine the direction of this relationship? One avenue would be to examine whether ability conceptions are affected on a specific or more global scale. If maintaining specific conceptions of ability is an important aspect of self-handicapping, we would expect self-handicapping to influence conceptions of ability only in that specific performance context. However, if maintaining global self-esteem is the predominant benefit of self-handicapping, we would expect that self-handicapping might influence more global beliefs of ability in a given domain and perhaps even other domains. Thus, the question is, "If a student self-handicaps prior to a chemistry test and subsequently fails, would the handicap protect only her perceived capability in chemistry? Would it also affect her perceived capability in academics as a whole, or perhaps would it even extend into other performance-related domains, such as athletics or social interaction?" To the extent that ability judgments are more globally affected, the idea that maintaining global self-esteem is the primary impetus underlying these judgments seems more plausible.

A second avenue to address these questions would be to conduct mediational analyses examining the relationships between attributions, ability ratings, and global selfesteem. We predict that the effects of self-handicapping on both ability ratings and global self-esteem should be mediated by performance attributions. However, when both ability ratings and global self-esteem are included in the same model, do changes in ability ratings mediate changes in global self-esteem or vice versa? Figure 1 depicts these two potential causal pathways. In the present study, we measured all of these variables and conducted mediational analyses to test these possible relationships.

\section{The Present Study}

The present study was designed to examine the consequences of self-handicapping for specific and global judgments of ability in domains related and unrelated to the 
performance as well as the relationship of these ability conceptions to self-esteem. We attempted to address this issue by examining the consequences of self-handicapping in a naturalistic setting (cf. Feick \& Rhodewalt, 1997). Students in an introductory psychology course served as participants. Claims of various types of handicaps were measured prior to an upcoming exam in the psychology course. We included a number of claims that were directly related to preparation for the test (i.e., study effort, attendance, etc.) as well as a stress inventory that captured other life events not directly connected to the test (i.e., working too much, roommate difficulties, etc.). ${ }^{1}$ Actual performance, postperformance attributions, current self-esteem, and ability ratings across a number of domains were measured in a session subsequent to the exam. By following participants over the course of the self-handicapping process, we could gain a more complete assessment of the consequences of selfhandicapping behavior.

A final goal of the current study was to examine the role of individual differences in the self-handicapping process. The role of individual differences in the tendency to self-handicap and make excuses prior to a performance (as measured by Jones \& Rhodewalt's [1982], Self-Handicapping Scale [SHS]) was examined, given that many previous studies (Hirt, Deppe, \& Gordon, 1991; Hirt, McCrea, \& Kimble, 2000; Rhodewalt \& Hill, 1995; Rhodewalt et al., 1991) have found that individuals scoring high on the scale differ significantly from individuals scoring low. Second, the role of sex in the selfhandicapping process was investigated because sex differences in self-handicapping have been reported in several studies (Hirt et al., 1991; Hirt, McCrea, et al., 2000; Rhodewalt \& Hill, 1995; Strube, 1986). Third, we included a measure of self-esteem because prior research has sometimes demonstrated interactions between self-esteem and level of self-handicapping (Rhodewalt et al., 1991; Smith \& Strube, 1991); we also included this measure to get a more reliable assessment of the changes in global self-esteem following performance.

\section{Predictions}

Consistent with past findings, we expected that highself-handicapping (HSH) individuals would claim more handicaps than low-self-handicapping (LSH) individuals. The effectiveness of these self-handicaps was expected to be seen on the attribution measures following performance. Those individuals scoring high on the SHS and claiming self-handicaps were predicted to attribute failure on the exam more to the handicap (e.g., lack of effort, stress) and less to ability. Despite the inconsistency of the evidence of self-handicappers' augmenting ability attributions, we expected that HSH individu- als in this study would display augmentation after a success, replicating Feick and Rhodewalt (1997).

We expected these attributions to have consequences both for global self-esteem and for ability beliefs. Consistent with Feick and Rhodewalt (1997) and Rhodewalt and Hill (1995), we predicted that HSH individuals who claimed the presence of self-handicaps would maintain global self-esteem despite poor performance. We also expected individuals who claim a handicap to maintain high ratings of their ability in psychology after failure (at a level comparable with those who did well), indicating that self-handicapping had been effective in maintaining specific ability beliefs despite failure. We were interested in examining whether this benefit of self-handicapping would carry over to more general ability conceptions or to other ability domains. We predicted that effects of selfhandicapping on self-ratings of psychology ability would be mediated by ability attributions. Finally, we wanted to assess whether ratings of psychology ability would in turn mediate the effects of performance attributions on global self-esteem, consistent with Berglas and Jones's (1978) original conceptualization of self-handicapping (see Figure 1b), or whether changes in global selfesteem would mediate the effects of attributions on ratings of ability in psychology or other domains (see Figure 1a).

\section{METHOD}

\section{Participants}

Participants were 158 introductory psychology students (68 men and 90 women) from Indiana UniversityBloomington. Participants received experimental credit in return for their participation. All participants were included in subsequent analyses, although several participants did not return for later sessions. For this reason, the actual number of participants varies slightly across sessions.

\section{Procedure}

Self-handicapping behaviors, test performance, and postperformance attributions and ability ratings were examined in a sample of introductory psychology students over the course of a semester. The data were collected over three sessions.

Session 1. During the first session, participants completed the SHS and the Rosenberg (1965) Self-Esteem Inventory. The SHS is a 25-item measure that uses a 6-point scale in a Likert format ranging from 0 (disagree very much) to 5 (agree very much) and has been used in many studies as a measure of the tendency of an individual to engage in self-handicapping behaviors and make excuses in a variety of domains. The scale contains items of a general nature, concerning effort (e.g., "I would do 
a lot better if I tried harder"), emotion and stress (e.g., "Sometimes I get so depressed that even easy tasks become difficult"), and excuse making (e.g., "I admit that I am tempted to rationalize when I don't live up to others' expectations"). The Rosenberg (1965) measure is a 10-item measure that uses a 7-point scale in a Likerttype format ranging from 1 (strongly agree) to 7 (strongly disagree) and is generally accepted as a satisfactory measure of global self-esteem. These measures were part of a larger mass survey given to introductory psychology students at the beginning of the semester. Participants also indicated their introductory psychology course section and meeting time. Participants for the remainder of the study were then recruited from the first session.

Session 2. The second session took place after the participant had taken at least one exam in his or her introductory psychology course; it occurred approximately 3 to 6 days prior to the next exam. Instructors were contacted to obtain the timing of upcoming tests for each introductory psychology course. Participants were then contacted by phone and scheduled according to the above criteria. During the second session, participants were told that because plans were being made by the department to change the format of the introductory psychology course, the researchers were interested in learning students' perceptions, views, and feelings about the current format of the course. Participants then completed a questionnaire that presumably would be used by the department in guiding these changes. The questionnaires included a number of demographic items, along with specific questions of how students felt about their introductory psychology course and college in general. An open-ended question concerning the participants' opinions and suggestions for changing the course was also included to solidify the cover story. Included in these questions were items assessing the participants' last test score (usually their second or third exam) to give us a baseline estimate of performance, as well as items assessing their expectations for the upcoming test (e.g., predicted score).

Claimed handicapping measures. Claims of exam preparatory behaviors included assessments of time spent studying for the next exam so far (in hours) and expected total time studying for the next exam (in hours). Participants were also asked to rate, using a scale from 1 (not at all) to 7 (very much), their attendance, textbook reading, and note taking since the last exam, as well as their estimated total effort toward the next exam.

Participants also completed a stress inventory. Participants were asked to check any of 45 common types of stress they might have experienced during the past few weeks (e.g., "roommate difficulties," "concerns about future," "working too many hours") (cf. Hirt et al.,
1991). For those items checked, participants were asked to rate the severity of the stressor on a scale from 1 (somewhat severe) to 3 (extremely severe).

Session 3. The final session was held approximately 1 week after participants had completed their next exam. Participants were again contacted by phone and scheduled based on these criteria.

Performance. In the final session, participants completed a questionnaire that included an item concerning their actual performance on their latest exam. Participants were asked to provide the number correct out of the number possible that they had received on the exam.

Attributions, self-esteem, and ability ratings. Participants indicated, using a scale from 1 (not at all) to 7 (very much), the degree to which their score was due to ability. Participants then completed a series of measures assessing their mood and self-esteem following the test (cf. Feick \& Rhodewalt, 1997). These measures consisted of items from McFarland and Ross's (1982) Resultant SelfEsteem Scale. Participants were asked to indicate how self-descriptive each of a series of 20 trait terms was (as they were "feeling right now") on a 1 (not at all) to 11 (extremely) scale. The scale provides three subscales that are factor analytically derived: Negative Affect (seven items: disappointed, discouraged, upset, frustrated, depressed, angry, and worried; $\alpha=.95$ ), Positive Affect (seven items: satisfied, excited, delighted, happy, contented, joyful, and pleased; $\alpha=.98$ ), and Self-Esteem (six items: smart, proud, confident, capable, stupid [reverse scored], and incompetent [reverse scored]; $\alpha=.93$ ). Finally, participants provided beliefs of their abilities in a variety of domains. These items were adapted from the Self-Attributes Questionnaire (SAQ) (Pelham \& Swann, 1989). Using a 10-point scale from A (bottom $5 \%$ ) to J (top 5\%), participants ranked their ability, relative to other college students of the same age, in academics, social competence, athletics, artistic/musical creativity, and most relevant, psychology. After the final session was complete, participants were fully debriefed and thanked for their participation.

\section{RESULTS}

\section{Overview}

The correlations between the main dependent measures are displayed in Table 1 . The effects of trait selfhandicapping, sex, and self-esteem on each of the dependent variables were investigated using a regression approach. Although most studies of self-handicapping have used a median split to create dichotomous individualdifference variables and proceeded to conduct ANOVAs, regressions are a more appropriate analysis in that it takes advantage of the continuous nature of these 
Table 1: Means, Standard Deviations, and Intermeasure Correlations

\begin{tabular}{|c|c|c|c|c|c|c|c|c|c|c|c|}
\hline Measure & PREP & STRES & OUT & $A T T R$ & PSE & $P A F F$ & $A C A$ & $S O C$ & $A T H$ & $C R E$ & PSYCH \\
\hline Claims of poor preparation (PREP) & - & .04 & $-.32 * * *$ & -.07 & .02 & .07 & -.08 & .08 & .09 & .05 & $-.21 * * *$ \\
\hline Claims of stress (STRES) & & - & -.07 & .03 & $-.20 *$ & -.08 & -.13 & -.08 & $-.29 * *$ & .02 & -.13 \\
\hline Test outcome (OUT) & & & - & $.27 * *$ & $.49 * * *$ & $* .69 * * *$ & .09 & $.17 *$ & .03 & -.04 & $.31 * *$ \\
\hline Ability attribution (ATTR) & & & & - & $.45^{* * *}$ & $* .48 * * *$ & .04 & $-.25^{* *}$ & -.14 & $-.24 * *$ & $.18^{*}$ \\
\hline Posttest self-esteem (PSE) & & & & & - & $.87 * * *$ & $.19 *$ & .02 & .13 & -.04 & $.46^{* * *}$ \\
\hline Posttest affect (PAFF) & & & & & & - & .06 & -.10 & .08 & -.11 & $.31 * *$ \\
\hline \multicolumn{12}{|l|}{ Self-ratings } \\
\hline Academic ability (ACA) & & & & & & & - & $.26 * *$ & .10 & $.20^{*}$ & $.51 * * *$ \\
\hline Social competence (SOC) & & & & & & & & - & $.19 *$ & $.24 * *$ & $.21^{*}$ \\
\hline Athletic ability (ATH) & & & & & & & & & - & $.16^{*}$ & $.19 *$ \\
\hline Creativity (CRE) & & & & & & & & & & - & $.18^{*}$ \\
\hline Psychology ability (PSYCH) & & & & & & & & & & & - \\
\hline$M$ & 23.12 & 31.30 & -.101 & 5.02 & 39.02 & 0.92 & 6.96 & 7.29 & 6.33 & 6.67 & 6.15 \\
\hline$S D$ & 5.53 & 19.63 & .120 & 1.52 & 14.65 & 40.57 & 1.19 & 1.58 & 2.07 & 1.82 & 1.65 \\
\hline
\end{tabular}

$* p<.05 . * * p<.01 . * * * p<.001$.

variables. References to HSH or LSH, HSE or LSE, and so forth, will indicate simple slopes calculated for one standard deviation above or one standard deviation below the mean, respectively (cf. Aiken \& West, 1991). All variables were centered by subtracting the mean. Despite the fact that no significant differences were obtained on first-exam performance, $F(7,124)=1.43$, $n s$, we included previous performance in the regression models to establish that any effects obtained on the dependent measures were independent of differences in previous performance. Predictor variables were entered into the regression equation as follows: Previous performance was entered as a first step, followed by the main effects of the three individual difference variables (sex, self-esteem, and SHS score) as the second step, followed by the two-way interactions of these individual difference variables as the third step, with the three-way interaction as a fourth step. Thus, a total of eight terms were included in the final regression model. Effects from the final model are reported in the text. After the initial set of regressions were performed on all of the dependent variables, a series of more complex regressions were conducted to investigate questions of mediation.

\section{Multiple Regression Results}

\section{SELF-HANDICAPPING MEASURES}

We included several measures of reported handicapping, including assessments of exam preparatory behaviors and claims of stress. The correlations among these different types of handicaps were very low $(r=.04, n s)$; thus, we report the results obtained for each type of handicap separately.

Claims of poor preparation. Our assessment of claimed (lack of) preparatory behaviors consisted of four measures (i.e., attendance, note taking, textbook reading, and overall effort and preparation for the upcoming exam) as well as two questions assessing study time (hours spent studying so far, total number of hours they intended to study). The reliability for the combined measure was acceptable $(\alpha=.74)$.

The regression model was highly significant, $F(8,121)=$ $4.27, p<.001\left(R^{2}=.22\right)$. The individually significant terms were main effects of sex $(\beta=.42, t=4.28, p<.001)$ and trait self-handicapping $(\beta=.22, t=2.07, p<.05)$. Men and HSH individuals claimed to have put forth less preparation for the exam than did women and LSH individuals. The three-way interaction of sex, trait self-handicapping, and self-esteem was also significant $(\beta=.20, t=1.98, p<$ $.05)$. Follow-up analyses probing the three-way interaction (cf. Aiken \& West, 1991) revealed that it was the HSEHSH men who claimed the least amount of effort in comparison with all other groups (simple slope $\beta=-.24, t=$ $3.07, p<.01$ ). In summary, claims of preparatory behaviors differed according to sex and trait self-handicapping, consistent with previous work (Hirt et al., 1991). HSEHSH men were particularly prone to report poor exam preparation. These effects were independent of previous performance in the course.

Self-reported stress. Stress scores were calculated by summing the severity scores for all of the stressors checked on the stress inventory. The stress measure therefore included both the frequency and the severity of reported stress. This analysis revealed a significant fit to the model, $F(8,123)=5.39, p<.001\left(R^{2}=.26\right)$. As expected, the main effect of trait self-handicapping was significant ( $\beta=.24, t=2.26, p<.03)$, such that HSH individuals reported experiencing more stress than did LSH individuals. Main effects of self-esteem $(\beta=.22, t=2.18, p<.05)$ and $\operatorname{sex}(\beta=.25, t=2.72, p<.01)$ also were found, indicating that women and LSE individuals reported more 
stress than did men and HSE individuals. There were no other significant effects on the stress variable. Thus, unlike the claimed preparatory behaviors measure, no interactions were obtained, indicating that both male and female HSH individuals claimed stress as a selfhandicap, whereas HSE-HSH men in particular claimed to engage in effort withdrawal. Interestingly, these results parallel the sex differences obtained when comparing direct measures of behavioral handicapping (i.e., effort withdrawal) with claims of stress in other studies (cf. Hirt et al., 1991).

\section{PERFORMANCE OUTCOME}

To be consistent with Feick and Rhodewalt (1997), we calculated our test outcome variable by subtracting participants' expected score from their actual score. Positive numbers indicate that the outcome exceeded expectations, whereas negative numbers indicate that the outcome fell short of expectations. However, analyses were performed separately on just the actual score, and the results parallel those reported here. ${ }^{2}$ The overall regression model was significant, $F(8,122)=2.28, p=.04$ $\left(R^{2}=.10\right)$. A main effect for trait self-handicapping was found $(\beta=.23, t=2.15, p<.05)$, such that HSH individuals performed considerably more poorly than LSH individuals. Thus, performance on the second exam was significantly affected by trait self-handicapping, independent of previous performance. No other individual terms significantly predicted test outcome.

Given that trait self-handicapping predicted test outcome, we then performed another regression analysis to see if claims of preparatory behaviors and/or stress mediate the observed differences in exam performance. This analysis revealed that claims of preparatory behaviors significantly predicted test outcome $(\beta=-.32, t=-3.46$, $p<.001, R^{2}$ change $=.08$ ). The addition of this term also reduced the effects of trait self-handicapping to nonsignificance $(\beta=.14, t=1.25, n s)$, indicating that claims of poor preparation mediated the effects of trait self-handicapping on performance. However, the addition of the claimed stress term (either alone or along with the claimed preparation measure) did not predict test outcome $(\beta=.06, t<1, n s)$. Thus, it appears that claims of poor preparation uniquely mediate the effects of trait self-handicapping on test outcome.

\section{ABILITY ATTRIBUTIONS}

Consistent with Feick and Rhodewalt (1997), we predicted a significant interaction between claimed handicaps and test outcome such that students would make lower ability attributions for failure (i.e., discount) the greater the amount of claimed handicaps but would make more extreme ability attributions for success (i.e., augment) the greater the amount of claimed handicaps. To test this prediction, test outcome was entered into the regression model as a fifth step, along with all possible interactions of test outcome with the individual difference variables. As a final step, the two measures of claimed self-handicapping (preparatory behaviors, stress) were entered, followed by the interactions between each of these measures and test outcome. Thus, a total of 20 terms were included in the final regression model.

This prediction was supported in the overall regression model, $F(20,95)=2.38, p<.01\left(R^{2}=.33\right)$. The individually significant predictors were test outcome $(\beta=.49$, $t=4.05, p<.001)$ and the Test Outcome $\times$ Claimed Preparatory Behaviors interaction $(\beta=.42, t=3.79, p<.01)$. Interpretation of this interaction, following the procedure outlined by Aiken and West (1991), indicated that the slope for failure students was negative $(\beta=-.41)$ and significantly different from zero $(t=-4.14, p<.001)$, whereas the slope for success students was positive $(\beta=$ $.27)$ and significantly different from zero $(t=2.53, p<$ $.01)$; that is, students attributed failure less to ability the greater the amount of claimed poor preparation but attributed success more to ability the greater the amount of claimed poor preparation. Thus, evidence for both augmenting and discounting was obtained for ability attributions. Interestingly, no effects were obtained for claims of stress. As was the case with test outcome, it appears that claims of poor preparation were critical for ability attributions, whereas claims of stress were not.

\section{POSTTEST SELF-ESTEEM}

The overall regression model predicting posttest selfesteem was significant, $F(20,95)=5.26, p<.001\left(R^{2}=\right.$ $.53)$. Individually significant terms included trait level of self-esteem $(\beta=.20, t=1.98, p<.05)$, prior test performance (i.e., first test score, $\beta=.19, t=2.42, p<.02$ ), test outcome $(\beta=.65, t=6.50, p<.001)$, and Test Outcome $\times \operatorname{Sex}(\beta=.25, t=2.55, p<.02)$. The Test Outcome $\times$ Sex interaction indicated that women's self-esteem was more greatly affected by failure on the test than was men's (simple slope $\beta=.38, t=3.70, p<.001$ ); no sex differences were obtained in reaction to success (simple slope $\beta=.05, t<1, n s)$. Interestingly, for this measure, both measures of claimed handicapping predicted selfesteem: claimed poor preparation, $\beta=.18, t=2.03$, $p<$ .05 ; claims of stress, $\beta=.16, t=1.82, p=.07$. There were no interactions by test outcome, indicating that students had higher self-esteem following either success or failure the greater the amount of claimed handicapping. Thus, both forms of handicapping had a buffering effect on global self-esteem following the test.

\section{POSTTEST MOOD}

Given that the two mood subscales were highly correlated $(r=-.83, p<.0001)$, we combined them into a single mood index (Positive Affect-Negative Affect), simi- 
lar to Feick and Rhodewalt (1997). The regression model predicting mood was highly significant, $F(20,95)=$ $9.77\left(p<.001, R^{2}=.67\right)$. The individually significant terms were prior test performance $(\beta=.14, t=2.14$, $p<$ $.05)$, test outcome $(\beta=.86, t=10.02, p<.0001)$, and the Test Outcome $\times$ Sex interaction $(\beta=.21, t=2.20, p<.05)$. Of the two claimed handicapping measures, only claimed poor preparation $(\beta=.23, t=3.15, p<.01)$ significantly affected mood. Claims of stress $(\beta=.05, t=0.70$, $n s$ ) did not predict mood. There were no interactions by test outcome, indicating that students' posttest mood was more positive following either success or failure the greater the amount of claimed effort withdrawal. Thus, whereas both forms of handicapping had a buffering effect on global self-esteem following the test, only claims of preparatory behaviors maintained mood.

\section{ATTRIBUTIONAL MEDIATION OF}

POSTTEST SELF-ESTEEM AND MOOD

Feick and Rhodewalt (1997) investigated whether ability attributions mediated the effects of claimed handicaps on posttest self-esteem and affect. Indeed, the original self-handicapping model proposed by Jones and Berglas (1978) argued that self-handicapping is an attributionally mediated phenomenon. These authors found that performance attributions mediated the effects of claimed handicaps on self-esteem but not affect. To investigate this possibility, we reran the regressions adding in two terms (ability attributions and Ability Attributions $\times$ Test Outcome) to the model. For selfesteem, the addition of these terms resulted in a significant increase in $R^{2}$ ( $R^{2}$ change $\left.=.06, F=6.18, p<.02\right)$. Both the ability attribution $(\beta=.21, t=2.49, p<.02)$ and the Ability Attribution $\times$ Outcome term $(\beta=.31, t=3.50$, $p<.001)$ contributed significantly to the model. Tests of the simple slopes (Aiken \& West, 1991) indicated that for failure, the slope was negative $(\beta=-.27, t=3.11, p<.01)$, such that self-esteem was higher the less students attributed their failure to ability; for success, the slope was positive $(\beta=.41, t=3.50, p<.01)$, such that self-esteem was higher the more they attributed their success to ability. Moreover, with these terms included in the model, the effects of claimed preparatory behaviors and selfreported stress were both reduced to nonsignificance ( $\beta \mathrm{s}=.16$ and .12 , respectively), indicating that ability attributions mediated the effects of claimed handicaps on self-esteem. A similar analysis on the posttest mood measure revealed that ability attributions showed a quite different pattern. The addition of the two ability attribution terms to the model did not significantly improve prediction $\left(R^{2}\right.$ change $\left.=.01, F=1.86, n s\right)$, nor did it affect the relationship between claims of poor preparation and posttest affect. Thus, as in Feick and Rhodewalt (1997), we found that the effects of claimed self-handicapping on posttest self-esteem were attributionally mediated, whereas the effects on mood were not.

\section{ABILITY RATINGS}

As can be seen in Table 1, the five ability ratings (i.e., academic ability, social competence, athletic ability, artistic/musical creativity, and ability in psychology) were only modestly correlated with one another. Correlations ranged in magnitude from .11 to .26 , with the exception of the correlation between academic ability and psychology ability $(r=.51)$. A MANOVA performed on these five ratings revealed main effects of sex, $F(1$, $134)=13.96, p<.001$, and trait level of self-esteem, $F(1$, $134)=3.71, p<.05$, such that men and HSE individuals rated themselves as having higher ability overall than women and LSE individuals. However, there were interactions of Rating and Sex, $F(4,536)=2.40, p<.05$, and Rating and Trait Self-Handicapping, $F(4,536)=2.72, p<$ .05 , which indicated that the effects of these individual difference variables differed across the various ratings. Thus, we performed separate regression analyses on each of the different ability ratings.

The regression analyses for the social competence rating obtained only a main effect of trait self-esteem, whereas the athletic ability and artistic/musical creativity ratings revealed main effects of both trait self-esteem and sex. Men rated themselves higher in athletic ability overall and women rated themselves higher in artistic/musical creativity overall. No effects of trait self-handicapping, claims of self-handicaps, or ability attributions were obtained on any of these measures. The regression model for the academic ability rating, $F(20,95)=2.02$, $p<.02\left(R^{2}=.30\right)$ found main effects of prior exam performance $(\beta=.30, t=3.11, p<.01)$ and test outcome $(\beta=$ $.23, t=2.10, p<.05)$, as well as main effects of $\operatorname{sex}(\beta=.34$, $t=2.79, p<.01)$ and trait self-esteem $(\beta=.24, t=1.80, p=$ $.07)$. Those individuals who received higher scores on either exam rated their academic ability higher than did those who received lower scores. However, again, no significant effects of trait self-handicapping or claims of handicaps were obtained on this measure. Thus, it does not appear that self-handicapping influenced ratings of general academic ability.

However, a different pattern emerged when we examined just the specific ratings of psychology ability. The regression model was highly significant, $F(20,95)=5.50$, $p<.001\left(R^{2}=.54\right)$. Both prior exam performance $(\beta=$ $.24, t=2.88, p<.01)$ and test outcome $(\beta=.21, t=2.09, p<$ $.05)$ again significantly predicted psychology ability ratings. Here, a main effect of trait self-handicapping also was found $(\beta=.28, t=2.41, p<.02)$, such that HSH individuals rated themselves higher in psychology ability than did LSH individuals. An interaction of Sex, SelfEsteem, and Trait Self-Handicapping also was obtained 
on this measure $(\beta=.34, t=2.55, p<.02)$. HSE-HSH men rated themselves significantly higher in psychology ability than did the other groups (simple slope $\beta=.46, t=$ $2.68, p<.01)$, despite the fact that they performed quite poorly on the exam. Finally, we found that claims of poor preparation significantly predicted ratings of psychology ability $(\beta=.40, t=4.56, p<.0001)$. The addition of this predictor alone increased the overall $R^{2}$ by .094 . Neither claims of stress nor the interactions of either claimed handicap with test outcome contributed significantly to the prediction of psychology ability ratings.

In summary, it appears that self-handicapping serves to maintain perceptions of competence in a specific domain (psychology ability) rather than more general perceptions of academic ability or global perceptions of self-worth across a wide variety of domains. On the measure of psychology ability, HSE-HSH men in particular rated themselves high in ability regardless of their performance. Thus, for these individuals, perceptions of high ability were maintained despite poor performance because they could blame their lackluster performance on their poor preparatory behavior.

\section{ATTRIBUTIONAL MEDIATION OF}

PSYCHOLOGY ABILITY RATINGS

As with posttest self-esteem and mood, we examined whether the effects of claimed handicaps on ratings of psychology ability were attributionally mediated. The addition of the two ability attribution terms to the model again resulted in a significant increase in $R^{2}$ ( $R^{2}$ change $=$ $.05, F=3.96, p<.05)$. Both the ability attribution $(\beta=.21$, $t=2.16, p<.05)$ and the Ability Attribution $\times$ Outcome term $(\beta=.20, t=2.16, p<.05)$ contributed significantly to the model. As with posttest self-esteem, psychology ability ratings were higher after failure the less students attributed their failure to ability (simple slope $\beta=-.37$, $t=3.11, p<.01)$, whereas psychology ability ratings were higher after success the more they attributed their success to ability (simple slope $\beta=.39, t=3.31, p<.01$ ). Although the addition of these terms did reduce the magnitude of the other effects in the model, these effects remained significant, suggesting that attributions only partially mediated the effects of individual differences and claims of poor preparation on ratings of psychology ability.

\section{SPECIFIC ABILITY RATINGS OR GLOBAL \\ SELF-ESTEEM: WHAT MEDIATES WHAT?}

Given that we found that both global self-esteem and ratings of psychology ability were attributionally mediated, our final question concerned whether one of these two variables mediated the other. To address this question, we performed a final set of regressions in which we added the global self-esteem term to the regression model predicting psychology ability ratings and added the psychology ability rating term to the model predicting global self-esteem. These analyses revealed that global self-esteem did marginally increase the prediction of psychology ability ratings $\left(R^{2}\right.$ change $=.02, F=3.66, p<$ .10). However, the addition of this term to the model had a negligible effect on the magnitude of the other terms, indicating that global self-esteem did not mediate the relationships between these variables on psychology ability ratings. In contrast, the addition of the psychology ability rating term significantly increased the prediction of global self-esteem $\left(R^{2}\right.$ change $\left.=.05, F=16.01, p<.001\right)$. Moreover, the addition of this term to the model $(\beta=.31$, $t=4.00, p<.001)$ reduced the magnitude of the ability attribution $(\beta=.14, t=1.71, p>.05)$ and the Ability Attribution $\times$ Outcome terms $(\beta=.17, t=1.95, p>.05)$ to nonsignificance. Thus, our results suggest that, consistent with Figure 1b, it is changes in perceived ability in the specific domain that mediate changes in global selfesteem resulting from self-handicapping. ${ }^{3}$

\section{DISCUSSION}

As expected, HSH individuals claimed both poor exam preparation and greater stress. They experienced impaired test performance yet were able to attribute their poor performance to the handicap, allowing them to maintain global self-esteem (cf. Feick \& Rhodewalt, 1997; Rhodewalt \& Hill, 1995). In addition, the present study found that high self-handicappers rated their ability in psychology as superior, illustrating that self-handicapping also allows individuals to preserve conceptions of ability in a specific domain. The findings also indicated that important distinctions can be made between different types of claimed handicaps. In the present study, only claims of poor exam preparation influenced attributions, posttest self-esteem and mood, and specific ability ratings. Finally, sex differences in the selection and effectiveness of self-handicapping strategies were also found. Each of these findings are discussed in turn.

\section{Global Self-Esteem and Self-Conceptions of Ability}

The present study nicely replicates Feick and Rhodewalt (1997) in demonstrating that claimed selfhandicapping maintains feelings of global self-esteem. Both claims of poor preparation and stress served to maintain self-esteem, despite poor test performance. Moreover, consistent with the original self-handicapping model (Jones \& Berglas, 1978), the effects of claimed handicaps on self-esteem were attributionally mediated. Following failure, self-handicappers were able to maintain self-esteem to the extent that they discounted ability as the cause of their performance; following success, selfhandicappers showed elevated self-esteem to the extent that they augmented ability attributions for their performance. Thus, our data clearly support the notion that 
claimed self-handicapping serves to effectively maintain global self-esteem.

However, the present study found evidence that selfhandicapping also serves another goal; namely, the goal of maintaining beliefs or conceptions of ability in a specific domain. High self-handicappers reported positive conceptions of their psychology ability despite the fact that they scored significantly more poorly on the exam. Again, this effect was mediated by claims of poor exam preparation and attributions; that is, individuals who claimed poor preparation and then attributed their poor performance to the handicap instead of ability were able to maintain quite positive perceptions of their own psychology ability.

But are the effects of self-handicapping on ability ratings unique from its effects on global self-esteem? Would you not expect that people who feel good about themselves after a test might then rate their ability in that domain higher? Indeed, several aspects of our data suggest that these effects are unique. First, it is important to note that only ability ratings in psychology were affected by self-handicapping; ratings of general academic ability or other unrelated abilities were not, demonstrating that the effects are remarkably specific. This finding seems at odds with a prediction derived from an argument that the ability ratings stem directly from feelings of global self-esteem. Furthermore, mediational analyses were performed to examine the nature of the relationship between posttest self-esteem and psychology ability ratings. The results of these path analyses illustrated that psychology ability ratings mediated changes in global self-esteem (consistent with the model depicted in Figure 1b), but global self-esteem did not mediate the effects observed for psychology ability ratings (contrary to the model depicted in Figure 1a). Thus, it appears that higher ratings of psychology ability result in better posttest self-esteem but that self-esteem changes do not mediate the effects of self-handicapping on ability ratings.

\section{Implications for the Motivation \\ Underlying Self-Handicapping}

Our findings have important implications for understanding the motivation underlying self-handicapping. To date, self-handicapping has been construed as a behavior motivated by the desire to preserve global selfesteem (cf. Feick \& Rhodewalt, 1997; Jones \& Berglas, 1978). Indeed, the extant evidence (including the present study) supports this contention. However, a difficult issue for this perspective to resolve is to explain why individuals would opt to self-handicap when there are myriad options available in the self-zoo (e.g., self-affirmation, SEM processes, etc.) that can accomplish the same underlying goal in a less costly manner. The present results indicate that an additional benefit derived from self-handicapping is the preservation of conceptions of ability in a specific domain (e.g., psychology). Thus, by self-handicapping, the individual not only is able to maintain positive self-regard in the face of poor objective performance but is able to maintain the belief that he or she has high levels of ability in that domain. We believe this additional benefit separates self-handicapping from alternative mechanisms that preserve global self-esteem, such as self-affirmation (Steele, 1988).

An important issue still to be examined is the relative prominence of these goals. One could question, for example, whether maintaining perceptions of ability is the primary goal of self-handicapping, with the benefit of sustaining global self-esteem an additional but secondary benefit, or whether maintaining global selfesteem (albeit through preserving positive ability conceptions) is still the ultimate goal. Fortunately, recent work by Tesser and his colleagues (Tesser \& Cornell, 1991; Tesser et al., 1996) provides an interesting avenue to address this question. Borrowing on Lewin's (1935) notions, Tesser argues that behaviors that serve the same underlying goal should substitute for each other. Several studies (Steele \& Liu, 1983; Tesser \& Cornell, 1991) have demonstrated that various self-protective mechanisms can indeed substitute for one another precisely because the different behaviors all serve the same underlying goal: namely, to maintain positive self-esteem and selfregard.

Extrapolating from this work, a logical next step would be to test whether these same sorts of processes might effectively substitute for self-handicapping. If indeed self-handicapping is primarily motivated by the goal of preserving self-esteem, we might expect that selfaffirmation or SEM processes (e.g., considering how one outperformed a close other in an important domain) should eliminate the need to self-handicap in a threatening evaluative situation. If, however, these alternative processes fail to substitute for self-handicapping, it suggests that preserving global self-esteem may not be the primary goal served by self-handicapping and that maintaining desired beliefs about competence in a particular domain may be the driving force underlying this behavior. We are currently conducting research along these lines in our lab.

\section{Behavioral Versus Claimed Self-Handicaps}

Issues of motivation are also of paramount importance to understanding the selection of self-handicapping strategies. Different types of self-handicaps may vary in their effectiveness as buffers for self-esteem and self-conceptions and may also differ in their consequences for other's impressions of the self-handicapper (Hirt, McCrea, \& Boris, 2000). It is clear from our results that 
claims of preparatory behaviors and stress had quite different effects for our participants. Previous studies using claimed handicaps have not distinguished among these different types of claims (Feick \& Rhodewalt, 1997; Rhodewalt \& Hill, 1995; Strube, 1986), although this distinction has been repeatedly shown to be important in actual behavior (cf. Hirt et al., 1991). In the present study, claims of poor preparation had a negative effect on test outcome and predicted ability attributions, posttest selfesteem, posttest affect, and psychology ability ratings. Claims of stress, on the other hand, had no effect on test outcome and only predicted posttest self-esteem. Thus, it appears that participants who claimed poor preparation were able to not only maintain self-esteem but also to maintain their desired self-conceptions about ability.

These results fit in well with the notions espoused by Hirt et al. (1991) regarding behavioral versus selfreported handicapping (cf. Leary \& Shepperd, 1986). These authors argued that behavioral handicaps (e.g., effort withdrawal) may be more effective in protecting self-esteem because they are more closely tied to performance than are self-reported handicaps (claiming stress). Indeed, no one can deny that a student who does not come to class, take notes, and read the book is likely to do poorly in a course. In the present study, even claims of these types of handicaps were detrimental, although it is unclear to what extent these claims were based in reality. Thus, individuals who self-handicap in this way have an undeniable excuse for poor performance and should be able to maintain self-esteem and self-conceptions of ability despite task failure. The present study clearly indicates that claims of effort withdrawal are likewise effective in fulfilling this function for the individual.

In contrast, Hirt et al. (1991) argued that selfreported handicaps, because they are less observable and only indirectly related to performance, may not be as effective in protecting the self as behavioral self-handicaps. They suggested that such behavior may be primarily intended as an impression management strategy. That is, claims of stress may serve as an effective excuse for external audiences (and thus may maintain self-esteem following poor performance) but not be believable enough to protect self-conceptions of ability. Although it would be premature at this point to assume that these differences would hold up for the entire range of behavioral and self-reported handicaps, the present data provide further evidence that distinguishing among these two different forms of handicapping is important because they may be motivated by different goals.

\section{Individual Differences}

Finally, consistent with past work, we found important individual differences in self-handicapping. Namely, HSE-HSH men were the individuals most prone to claim behavioral handicaps and to rate themselves high in psychology ability despite poor objective performance. The observed sex differences in the reporting of behavioral handicaps parallel the findings obtained in many studies of actual behavioral self-handicapping (Harris \& Snyder, 1986; Hirt et al., 1991; Rhodewalt \& Hill, 1995). Moreover, Rhodewalt et al. (1991) found that HSE-HSH men not only discounted ability attributions following failure but also were the sole group that augmented ability attributions following success in the presence of an external handicap. Indeed, Hirt, McCrea, et al. (2000) have argued that the behavior of HSH men in these studies consistently fits with the self-handicapping model (cf. Jones \& Berglas, 1978); however, what is difficult to understand is the behavior of HSH women in these studies. Although these individuals claim handicaps such as stress at a level comparable to HSH men, they neither engage in nor claim behavioral handicaps. Furthermore, the present study illustrates that although these claimed handicaps of stress may maintain self-esteem, they fail to afford HSH women the opportunity to maintain desired beliefs about ability following poor performance. The present results only serve to highlight the need for further research into the cause of these sex differences in self-handicapping.

In conclusion, we have attempted to document an important benefit of self-handicapping: protecting specific beliefs of ability in a threatened domain. Furthermore, our results indicate that the benefits of self-handicapping for global self-esteem derive from protection of these beliefs. Given that self-handicapping has these multiple functions, future research will need to examine the relative importance of these goals in the motivation to selfhandicap. The use of self-handicapping strategies over other, less destructive, self-protection strategies, and the preference for certain types of self-handicaps, may be a result of the interplay of these multiple motives.

\section{NOTES}

1. We refer to both types of self-handicaps as claims, although one could argue that the measures of preparatory effort may reflect actual behavioral self-handicaps. Because we have no independent assessment of participants' actual behavior, only self-reports, we cannot substantiate at this point the "reality" of the handicaps. Although there are clear differences between the two types of handicaps (e.g., one could say that claims of poor preparation have a more direct link to performance than claims of stress), we refer to both as claims to denote the fact that the measures of self-handicapping are merely self-reports. We address this issue at more length in the Discussion section.

2. We chose to use expected-actual as our outcome variable to be consistent with Feick and Rhodewalt (1997), thus creating a measure of self-defined success and failure. However, analyses performed on the actual performance measure separately revealed that the obtained pattern of results holds if we define outcome as simply actual score. A main effect of trait self-handicapping was still obtained $(\beta=-.24, t=$ $2.35, p<.05)$, indicating that high self-handicappers scored almost a full letter grade lower on the exam than did low self-handicappers ( $71 \%$ vs. $79 \%$ ). Expectations for the second exam, controlling for first 
exam performance, did not differ as a function of trait self-handicapping. Thus, it is not the case that the effects of outcome in the present research are affected by whether we define them relative to expectations.

3. To more fully address the question of mediation, we examined the effects of global self-esteem on the other self-ratings, as well as the effects of the other self-ratings on global self-esteem. Of importance, the inclusion of any of the other self-ratings in the regression model had no effect on the prediction of global self-esteem $\left(R^{2}\right.$ change $<.01$, $n s$ ), indicating that conceptions of psychology ability alone served as a mediator of the effects observed on global self-esteem. However, global self-esteem did serve as a predictor of self-ratings of academic ability $(\beta=.35, t=2.53, p<.05)$ and, to a slightly lesser extent, social competence $(\beta=.27, t=1.88, p=.063)$ and creativity $(\beta=.26, t=1.84, p=.069)$. Thus, it does appear that there is some evidence that changes in global self-esteem affect ability ratings, although they do not seem to mediate the effects of attributions on specific self-conceptions of psychology ability.

\section{REFERENCES}

Aiken, L. S., \& West, S. G. (1991). Multiple regression. Newbury Park, CA: Sage

Arkin, R. M., \& Baumgardner, A. H. (1985). Self-handicapping. In J. H. Harvey \& G. W. Weary (Eds.), Attribution: Basic issues and applications (pp. 169-202). New York: Academic Press.

Berglas, S., \& Jones, E. E. (1978). Drug choice as a self-handicapping strategy in response to noncontingent success. Journal of Personality and Social Psychology, 36, 405-417.

Feick, D. L., \& Rhodewalt, F. (1997). The double-edged sword of selfhandicapping: Discounting, augmentation, and the protection and enhancement of self-esteem. Motivation and Emotion, 21, 147163.

Harris, R. N., \& Snyder, C. R. (1986). The role of uncertain selfesteem in self-handicapping. Journal of Personality and Social Psychology, 51, 451-458.

Hirt, E. R., Deppe, R. K., \& Gordon, L. J. (1991). Self-reported versus behavioral self-handicapping: Empirical evidence for a theoretical distinction. Journal of Personality and Social Psychology, 61, 981991.

Hirt, E. R., McCrea, S. M., \& Boris, H. I. (2000). Audience reaction in selfhandicapping: A matter of who sees what in whom. Manuscript submitted for publication, Indiana University-Bloomington.

Hirt, E. R., McCrea, S. M., \& Kimble, C. E. (2000). Public self-focus and sex differences in behavioral self-handicapping: Does increasing self-threat still make it "just a man's game?" Personality and Social Psychology Bulletin, 26, 1131-1141.

Isleib, R. A., Vuchinich, R. E., \& Tucker, J. A. (1988). Performance attributions and changes in self-esteem following self-handicapping with alcohol consumption. Journal of Social and Clinical Psychology, 6, 88-103.

Jones, E. E., \& Berglas, S. (1978). Control of attributions about the self through self-handicapping strategies: The appeal of alcohol and the role of underachievement. Personality and Social Psychology Bulletin, 4, 200-206.

Jones, E. E., \& Rhodewalt, F. (1982). Self-Handicapping Scale. Unpublished scale, Department of Psychology, Princeton University and University of Utah.

Kelley, H. H. (1973). The processes of causal attribution. American Psychologist, 28, 107-128.
Kolditz, T. A., \& Arkin, R. M. (1982). An impression management interpretation of the self-handicapping strategy. Journal of Personality and Social Psychology, 43, 492-502.

Leary, M. R., \& Shepperd, J. A. (1986). Behavioral self-handicaps vs. self-reported handicaps: A conceptual note. Journal of Personality and Social Psychology, 51, 1265-1268.

Lewin, K. (1935). A dynamic theory of personality: Selected papers (D. E. Adams \& K. E. Zener, Trans.). New York: McGraw-Hill.

Mayerson, N. H., \& Rhodewalt, F. (1988). The role of self-protective attributions in the experience of pain. Journal of Social and Clinical Psychology, 6, 203-218.

McFarland, C., \& Ross, M. (1982). Impact of causal attributions on affective reactions to success and failure. Journal of Personality and Social Psychology, 43, 937-946.

Murray, C. B., \& Warden, M. R. (1991). Implications of self-handicapping strategies for academic achievement: A reconceptualization. Journal of Social Psychology, 132, 23-37.

Pelham, B. W., \& Swann, W. B. (1989). From self-conceptions to selfworth: On the sources and structure of global self-esteem. Journal of Personality and Social Psychology, 57, 672-680.

Rhodewalt, F., \& Hill, S. K. (1995). Self-handicapping in the classroom: The effects of claimed self-handicaps on responses to academic failure. Basic and Applied Social Psychology, 16, 397-416.

Rhodewalt, F., Morf, C., Hazlett, S., \& Fairfield, M. (1991). Selfhandicapping: The role of discounting and augmentation in the preservation of self-esteem. Journal of Personality and Social Psychology, 61, 122-131.

Rosenberg, M. (1965). Society and adolescent self-image. Princeton, NJ: Princeton University Press.

Smith, D. S., \& Strube, M. J. (1991). Self-protective tendencies as moderators of self-handicapping impressions. Basic and Applied Social Psychology, 12, 63-80.

Snyder, C. R. (1990). Self-handicapping processes and sequelae: On taking a psychological dive. In R. L. Higgins, C. R. Snyder, \& S. Berglas, (Eds.), Self-handicapping: The paradox that isn't (pp. 104150). New York: Plenum.

Snyder, C. R., \& Smith, T. W. (1982). Symptoms as self-handicapping strategies: The virtues of old wine in a new bottle. In G. Weary \& H. L. Mirel (Eds.), Integrations of clinical and social psychology (pp. 104-127). New York: Oxford University Press.

Steele, C. M. (1988). The psychology of self-affirmation: Sustaining the integrity of self. In L. Berkowitz (Ed.), Advances in experimental social psychology (Vol. 21, pp. 261-302). New York: Academic Press.

Steele, C. M., \& Liu, T. J. (1983). Dissonance processes as self-affirmation. Journal of Personality and Social Psychology, 45, 5-19.

Strube, M. J. (1986). An analysis of the Self-Handicapping Scale. Basic and Applied Social Psychology, 7, 211-234.

Tesser, A., \& Cornell, D. P. (1991). On the confluence of self-processes. Journal of Experimental Social Psychology, 27, 501-526.

Tesser, A., Martin, L. L., \& Cornell, D. P. (1996). On the substitutability of self-protective mechanisms. In P. M. Gollwitzer \& J. A. Bargh (Eds.), The psychology of action: Linking cognition and motivation to behavior (pp. 48-68). New York: Guilford.

Tice, D. M. (1991). Esteem protection or enhancement?: Selfhandicapping motives and attributions differ by trait self-esteem. Journal of Personality and Social Psychology, 60, 711-725.

Touhey, J. C., \& Villemez, W. J. (1980). Ability attribution as a result of variable effort and achievement motivation. Journal of Personality and Social Psychology, 38, 211-216. 